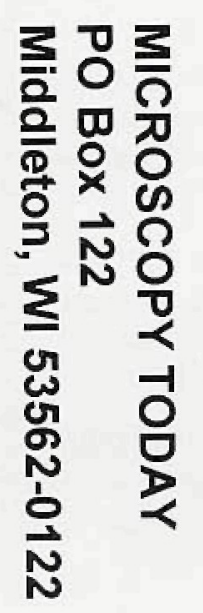

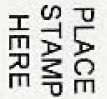

\title{
POSIIONS AVAILABLE
}

$\checkmark$ Seeking experienced analytical microscopists to work on polymer, metals, ceramic semiconductor and biological material projects. Specific experience in cryogenic ultramicrotomy, ion beam thinning and/or asbestos analysis a plus. Work includes studies for industrial, academic and legal elements. Send resume with salary history/expectations in confidence to Andrew Blackwood, Ph.D., Structure Probe, Inc., PO Box 656, West Chester, PA 19381-0656. No telephonecalls/smokers please.

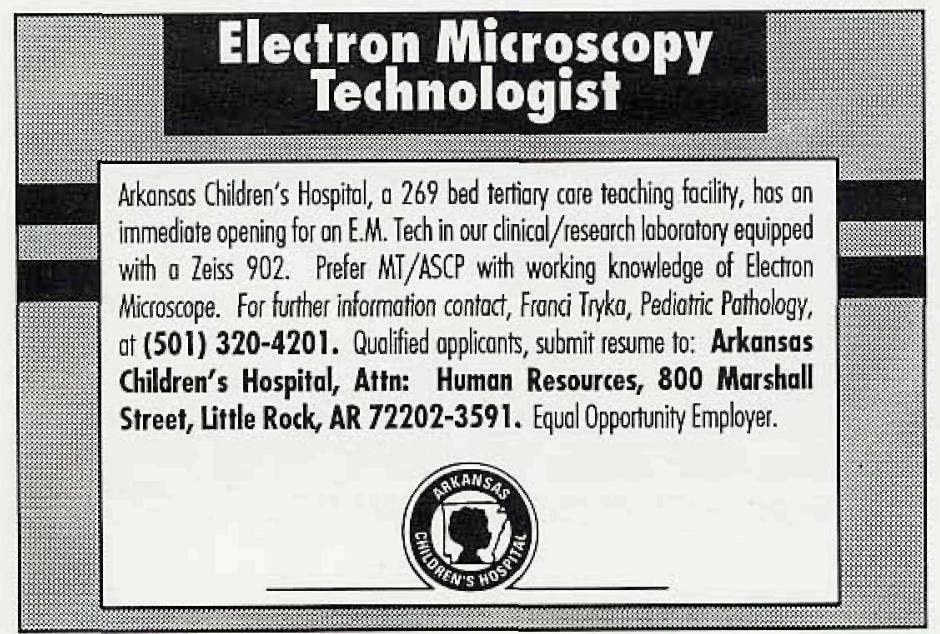

\section{Sputter/Carbon Coating the SPI-Module ${ }^{\text {TM }}$ Way}

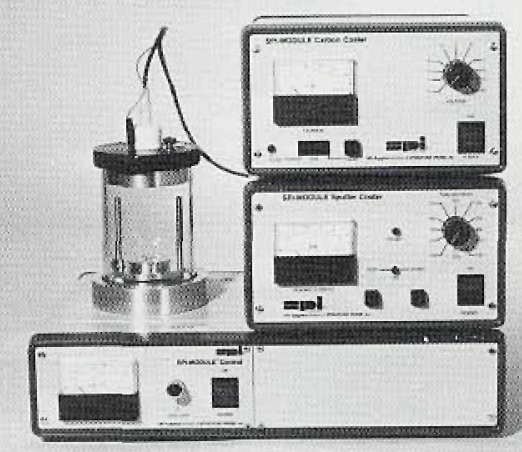

- "Fast" coating: minimal radiant heat

- "Cool" coating: virtually no electron damage

- Upgradable: add thickness monitor or etch mode

- Versatility: adjustable sample stage height

- Mobility: compact design allows for portability

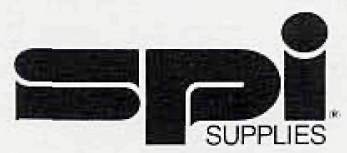

\section{Call us at: 1-800-2424-SPI}

